\title{
Prevalence of Childhood Obesity in Portugal: A Narrative Review of the Literature
}

\author{
Fátima Frade ${ }^{a, b}$ Dora Carteiro ${ }^{c, d}$ Fátima Pereirad, e Joana Marques ${ }^{f}$ \\ João Frade ${ }^{g, h, i}$

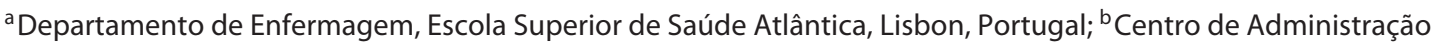 \\ e Politicas Públicas (CAPP), Lisbon, Portugal; ' UCSP Charneca do Lumiar ACES I - Lisboa Norte, Lisbon, Portugal; \\ dDepartamento de Enfermagem, Escola Superior de Saúde Atlantica, Lisbon, Portugal; ' Serviço de Urgência \\ Obstétrica e Ginecologica do Hospital São Francisco Xavier, Lisbon, Portugal; ${ }^{f}$ Departamento de Enfermagem, \\ Escola Superior de Saúde da Cruz Vermelha Portuguesa, Lisbon, Portugal; ${ }^{9}$ Departamento de Enfermagem, Escola \\ Superior de Saúde do Instituto Politécnico de Leiria, Leiria, Portugal; ${ }^{\text {h } C e n t e r ~ f o r ~ I n n o v a t i v e ~ C a r e ~ a n d ~ H e a l t h ~}$ \\ Technology, Politécnico de Leiria, Leiria, Portugal; ' Unidade Multidisciplinar de Investigação Biomédica, Instituto de \\ Ciências Biomédicas Abel Salazar, Universidade do Porto, Porto, Portugal
}

\section{Keywords}

Prevalence $\cdot$ Paediatric obesity · Child overweight · Portugal

\begin{abstract}
Background: The number of childhood obesity cases has been increasing in several countries around the world. In view of all the associated complications at an early stage of child development, it becomes urgent to understand this problem in depth. Objective: The aim of this work was to describe the prevalence of childhood obesity in Portugal and analyze the trend of its evolution in recent years. Materials and Methods: This is a narrative review of the literature in the databases on the following platforms: Academic Google, Scientific Electronic Library Online (SciELO), EBSCO Host, and Biblioteca Virtual em Saúde (BVS). The keywords used were: Prevalence, Pediatric Obesity, Child Overweight, and Portugal. Results and Discussion: Data on the preva-
\end{abstract}

lence of childhood obesity in Portugal are presented, describing the results of studies conducted at national and district level, in the different age groups and by sex. Conclusions: The data reveal that the prevalence of overweight in Portugal ranges between 20 and 40\%, and of obesity between 10 and 15\%, which reinforces the urgent need for monitoring and implementing preventive measures.

\section{(c) 2020 The Author(s). Published by S. Karger AG, Basel on behalf of NOVA National School of Public Health}

\section{Prevalência da obesidade infantil em portugal: uma revisão narrativa da literatura
Palavras Chave Portugal \\ Prevalência · Obesidade Infantil · Excesso de Peso ·}

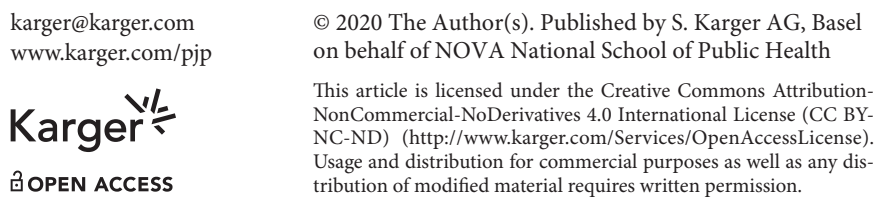

karger@karger.com www.karger.com/pjp

Karger $\stackrel{\text { ' }}{5}$

BOPEN ACCESS

(C) 2020 The Author(s). Published by S. Karger AG, Basel on behalf of NOVA National School of Public Health

This article is licensed under the Creative Commons AttributionNonCommercial-NoDerivatives 4.0 International License (CC BYNC-ND) (http://www.karger.com/Services/OpenAccessLicense). Usage and distribution for commercial purposes as well as any distribution of modified material requires written permission.

Fátima Frade

Departamento de Enfermagem, Escola Superior de Saúde Atlântica Fábrica da Pólvora de Barcarena

PT-2730-036 Barcarena, Lisbon (Portugal)

ffrade@ uatlantica.pt 


\section{Resumo}

Enquadramento: O número de casos de obesidade infantil tem vindo a aumentar em vários países de todo o mundo. Face a todas as complicações associadas num estádio precoce do desenvolvimento da criança, torna-se urgente conhecer aprofundadamente esta problemática. Objetivo: Descrever a prevalência da obesidade infantil em Portugal e analisar a tendência da evolução da mesma nos últimos anos. Material e Métodos: Consiste numa revisão narrativa da literatura recorrendo a bases de dados nas seguintes plataformas Google Académico, Scientific Electronic Library Online (SciELO), EBSCO Host, e Biblioteca Virtual em Saúde (BVS), com as palavras-chave: Prevalence, Pediatric Obesity, Child Overweight e Portugal. Resultados e Discussão: Foram apresentados os dados relativos à prevalência da obesidade infantil em Portugal, descrevendo e analisando a tendência dos resultados de estudos realizados a nível nacional e a nível distrital, nos diferentes grupos etários e por sexo. Conclusões: Os dados revelam que a prevalência de excesso de peso em Portugal se situa entre 20 a $40 \%$, e a da obesidade entre 10 a 15\%, o que reforça a necessidade urgente de monitorização e implementação de medidas de prevenção.

๑ 2020 The Author(s). Published by S. Karger AG, Basel on behalf of NOVA National School of Public Health

\section{Introduction}

Childhood obesity is reaching alarming proportions in many countries of the world and is an urgent and serious challenge to the health of children. Childhood obesity is one of the most serious challenges of Public Health of the 21 st century [1].

Worldwide prevalence has increased at a disturbing rate. In 2016, the number of children aged under 5 years who were overweight was around 41 million. Almost half of these children lived in Asia and a quarter lived in Africa [1].

Portugal is one of the five countries in the European Region with the highest prevalence of childhood obesity. Data for 2018-2019 reveal that in the population of children and adolescents the prevalence of overweight is $29.6 \%$ and childhood obesity is $12 \%$, that represents a prevalence of overweight of $41.6 \%$ (including obesity) $[2,3]$.

Overweight and obese children tend to remain obese in adulthood and are more likely to develop non-transmissible diseases, such as diabetes and cardiovascular diseases in the future [1]. Obesity has a negative impact on children's health and may be associated with co-morbidities, such as hypertension, dyslipidaemia, type 2 diabetes mellitus, sleep apnea, and orthopaedic and psychosocial problems, including discrimination, social isolation, and low self-esteem [4].

The identification and analysis of the prevalence of childhood obesity in Portugal allows us to understand the dimension of the need to implement prevention programs and the area of the country where it is necessary to prioritize this intervention.

The aim of this article is to describe the prevalence of childhood obesity in Portugal and to analyse the trend of its evolution in recent years.

\section{Materials and Methods}

In order to reach our objective a narrative review of the literature was carried out to gather knowledge about the prevalence of childhood obesity in the scope of public health, specifically for children's health [5], in Portugal. This review sought to describe the prevalence of childhood obesity in Portugal and to analyse the trend of its evolution in recent years, identify regions of the country where studies have been developed, determine which age groups of children were integrated in the studies carried out, and ascertain which criteria were used to assess these children's body mass index (BMI).

The search for articles was carried out on the following platforms: Google Academic, Scientific Electronic Library Online (SciELO), EBSCO Host, and Virtual Health Library (VHL), in the following databases: IBECS, CINAHL Complete, Library, Information Science and Technology Abstracts, and MEDLINE Complete. The inclusion criteria were: language (Portuguese, English, and Spanish), availability (full text), and time of publication (last 10 years). The Boolean conjugation of the descriptors were in English and Portuguese: (Prevalence) AND ([Paediatric Obesity] OR [Child Overweight]) AND (Portugal). Reference was also made to articles, books, and official documents.

The selected studies used different criteria for assessing the prevalence of childhood obesity and different criteria to evaluate BMI. These were the World Health Organization (WHO) criteria, the International Obesity Task Force (IOTF) criteria, the Centers for Disease Control and Prevention (CDC) criteria, and the French reference criteria. When addressing the prevalence of childhood obesity, overweight/overweight and obesity are considered. The CDC [6] criteria define overweight if the BMI percentile is $>85$ and $<95$, and obesity if the BMI percentile is $\geq 95$. According to the IOTF criteria [ 7,8$]$, in children aged from 2 to 18 years old cut-off points correspond to an adult BMI, thus overweight is defined for BMI percentiles $>25$ and $<30$, and obesity for a BMI percentile $\geq 30$. The WHO criteria $[8,9]$ defines overweight and obesity according to the weight-for-height $Z$-score distribution, that is the relationship between the weight measured and the ideal weight for height, or through the BMI percentile. Therefore, for children aged from 0 to 5 years old, overweight is determined if the BMI Z-Score is $>2$ and $\leq 3$ or BMI percentile is $>97$, and obesity is recorded if the BMI $Z$-score is $>3$ or BMI percentile is $>99$. For children aged 

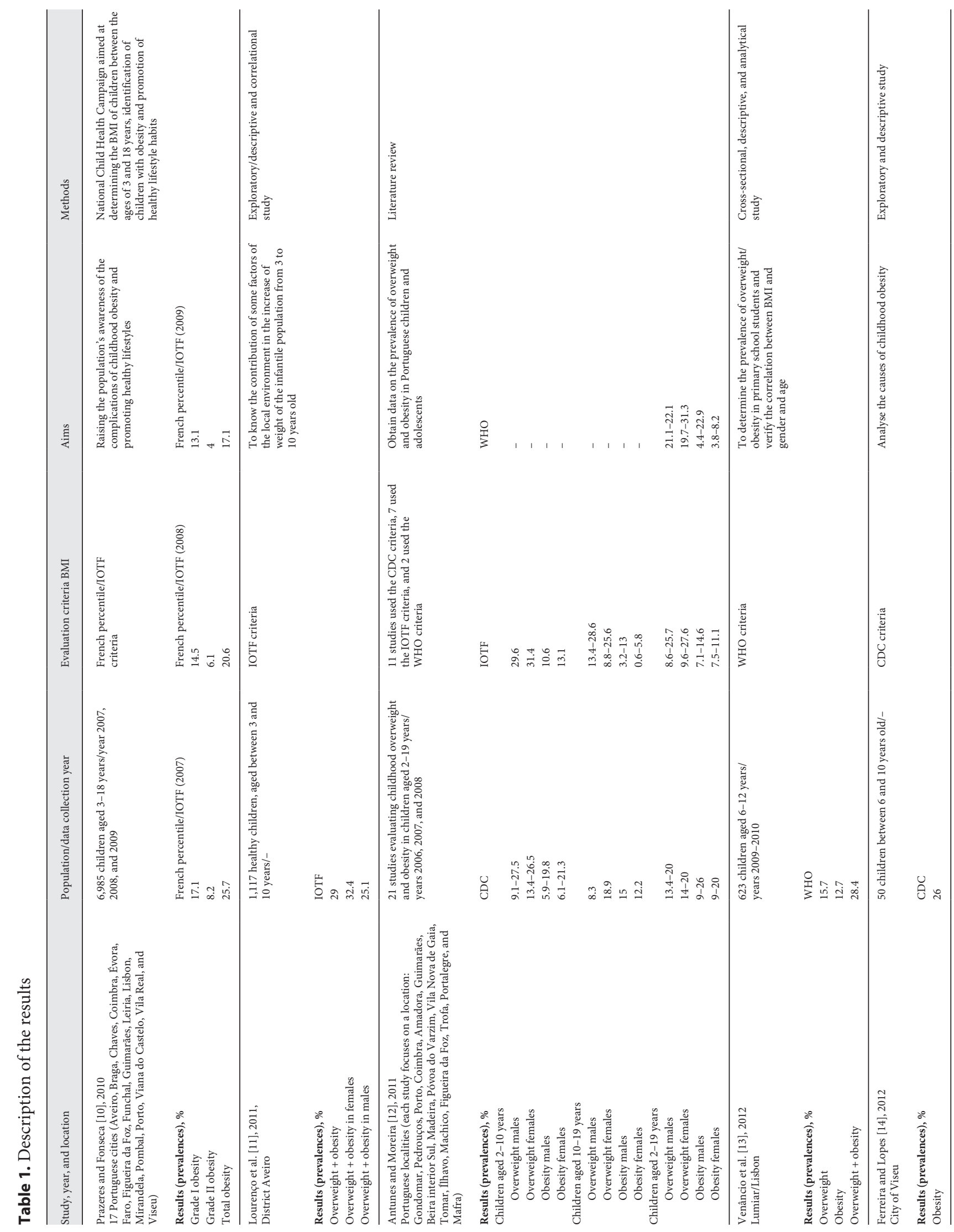


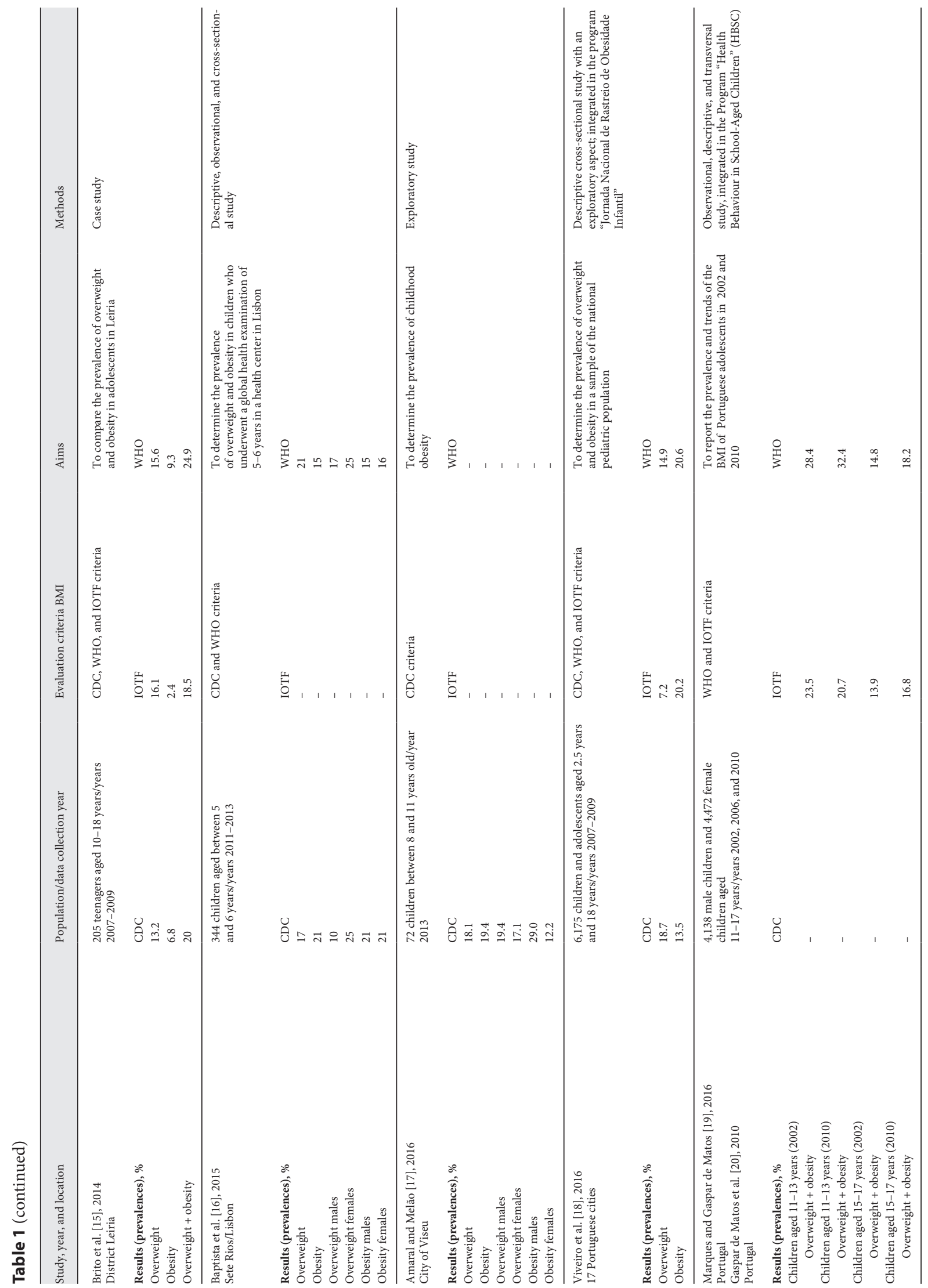




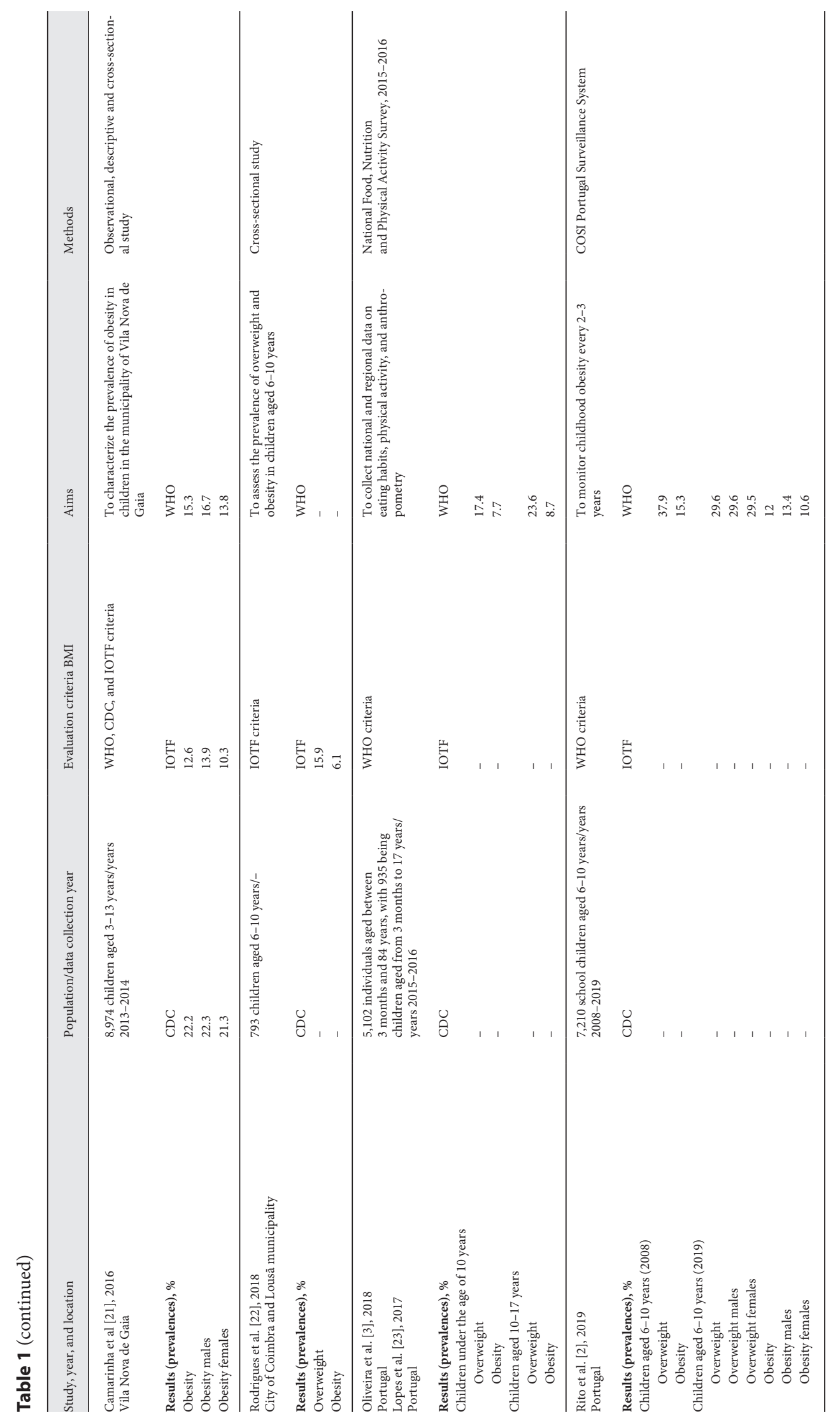


5-19 years, overweight is defined if the BMI $Z$-score is $>1$ and $\leq 2$ or the BMI percentile is $>85$, and obesity if the BMI $Z$-score is $>2$ or BMI percentile is $>97$. The French curve criteria [8] is similar to the IOTF criteria: for children up to 18 years of age, obesity/obesity grade II is defined if the BMI percentile is $\geq 30$ using the BMI cut-off points used for adults, and overweight/obesity grade $\mathrm{I}$ is defined if the BMI percentile is $\geq 97$.

\section{Results and Discussion}

From the research carried out, 13 articles and 3 official documents were selected which met the inclusion criteria $[2,3,10-23]$, the results of which are summarized in Table 1 . Of these documents, 1 was published in 2010 [10], 2 in 2011 [11, 12], 2 in 2012 [13, 14], 1 in 2014 [15], 1 in 2015 [16], 4 in 2016 [17-21], 2 in 2018 [3,22], and of the official documents, 1 in 2010 [20], 1 in 2017 [23], and 1 in 2019 [2].

As for the regions of the country covered in the surveys, 5 of these investigations were carried out at national level $[2,3,19,20,23], 3$ in different cities/locations around the country [10, 12, 18], 1 in Aveiro [11], 2 in Lisbon [13, 16], 2 in Viseu [14, 17], 1 in Leiria [15], 1 in Vila Nova de Gaia [21], and 1 in Coimbra [22]. With regard to the BMI evaluation criteria, 11 studies used the WHO criteria $[2,3,12,13,15,16,18-21,23], 7$ used the CDC criteria $[12,14-18,21], 9$ used the IOTF criteria $[10-12,15$, 18-22], and 1 used the French reference criteria [10].

With regard to samples, it should be noted that the studies by Prazeres and Fonseca [10] and Viveiro et al. [18] seem to analyse the results of the same sample; however, the authors of both articles used different analytical approaches. Viveiro et al. [18] analysed the overall results that included the 3 years of data collection and used the CDC, WHO, and IOTF BMI assessment criteria. Prazeres and Fonseca [10] analysed the results by year of research, and used the BMI evaluation criteria of the IOTF and French curves. Thus, both articles present results that enrich this literature review.

The results of the studies selected for this narrative review of the literature will be described chronologically in order to more clearly expose the trend of the prevalence of childhood obesity in Portugal. The prevalence of childhood obesity in Portugal is at the top of the list in relation to other European regions. This reality has raised concerns in the scientific community, which over recent years has carried out several studies at national level in order to identify the prevalence of obesity in Portugal.

The study published in 2010 collected data in a phased manner in 2007, 2008, and 2009 in 17 cities in Portugal
(Aveiro, Braga, Chaves, Coimbra, Évora, Faro, Figueira da Foz, Funchal, Guimarães, Leiria, Lisbon, Mirandela, Pombal, Porto, Viana do Castelo, Vila Real, and Viseu). Overall, the study focused on a sample of 6,985 children aged between 3 and 18 years, using the French percentile curves and the BMI IOTF assessment criteria. The results revealed that in 2007 the screened children had an obesity prevalence of $25.7 \%$, in 2008 the percentage of children with obesity was $20.6 \%$, and in 2009 the prevalence of obesity was $17.1 \%$. Of the 6,985 children assessed in the 3 years, the prevalence of obesity was $20 \%$. Considering the total sample, the analysis of the prevalence of obesity by year and age of the child showed that obesity is more prevalent in children aged between 6 and 12 years $(26.2 \%$ ) [10].

In the district of Aveiro, 1,117 children aged between 3 and 10 years were studied using the IOTF criteria. The results revealed that in the total sample the prevalence of overweight was 29\% (including obesity). Analysing the prevalence according to gender, it appears that girls had a higher prevalence of overweight and obesity (32.4\%) compared to boys (25.1\%) [11].

A review of the literature published in 2011 included 20 articles published in the years 2006, 2007, and 2008. The sample for each article covered one of the following Portuguese locations: Gondomar, Pedrouços, Porto, Coimbra, Amadora, Guimarães, Beira interior Sul, Madeira, Póvoa do Varzim, Vila Nova de Gaia, Tomar, Ílhavo, Machico, Figueira da Foz, Trofa, Portalegre, and Mafra. The objective was to describe the prevalence of childhood obesity in children and adolescents, and the study samples focused on children aged from 2 to 10 years (in a total of 6,002 children) using the CDC evaluation criteria. The prevalence of overweight varied between 9.1 and $27.4 \%$ in males and from 13.4 to $26.5 \%$ in females, and the prevalence of obesity ranged from 5.9 to $19.8 \%$ in males and between 6.1 and $21.3 \%$ in females. When using the IOTF criteria the prevalence of overweight was $29.6 \%$ for males and $31.4 \%$ for females, and the prevalence of overweight was $29.6 \%$ for males and $31.4 \%$ for females. Obesity was registered as $10.6 \%$ in males and $13.1 \%$ in females. Studies focusing on adolescents aged 10-19 years (with a sample of 1,911 adolescents) using the IOTF criteria revealed that the prevalence of overweight in males varied between 13.4 and $28.6 \%$, and in females between 8.8 and $25.6 \%$. With regard to obesity, for males it varied between 3.2 and $13 \%$ and for females between 0.6 and $5.8 \%$. In the studies that evaluated BMI using the CDC criteria, the overweight finding was $8.3 \%$ for men and $18.9 \%$ for women. The prevalence of obesity was $15 \%$ for males and $12.2 \%$ for females. In studies with a global sam- 
ple of children and adolescents (with a sample of 4,211 children and adolescents) using the CDC assessment criteria, the prevalence of overweight varied between 13.4 and $20 \%$ in males and between 14 and $20 \%$ in females. Obesity in males varied between 9 and 26\%, and in females between 9 and 20\%. In studies that used the IOTF evaluation criteria, the prevalence of overweight was between 8.6 and $25.7 \%$ for males, and between 9.6 and $27.6 \%$ for females. In relation to obesity, the values were between 7.1 and $14.6 \%$ for males and between 7.5 and $11.1 \%$ for females. Studies using the WHO criteria revealed that the prevalence of overweight was between 21.1 and $22.1 \%$ for males and between 19.7 and $31.3 \%$ for females. The prevalence of obesity in males was between 4.4 and $22.9 \%$, and between 3.8 and $8.2 \%$ for females [12].

In Lumiar/Lisbon, BMI was assessed by WHO criteria between 2009 and 2010 in 623 children aged 6-12 years. The results revealed that $15.7 \%$ of the children in the sample were overweight and that $12.7 \%$ were obese, with the prevalence of overweight being $28.4 \%$ (including obesity) [13].

A study published in 2012 was conducted in the city of Viseu in which BMI was assessed for 50 children aged from 6 to 10 years. According to the CDC criteria, the results revealed that $26 \%$ of these children were obese. There were no significant differences between obesity and age or obesity and sex [14].

In 2014 a study was published reporting data collected between 2007 and 2009 considering the prevalence of overweight and obesity in 205 adolescents aged 10-18 years from the region of Leiria. The WHO, CDC, and IOTF criteria were used to assess BMI. The results of this study tell us that according to the CDC criteria the overweight prevalence was $20 \%$ (including obesity), of which $13.2 \%$ were overweight adolescents and $6.8 \%$ were obese. In males, the prevalence was $15.2 \%$ for overweight and $7.6 \%$ for obesity. In females, $11 \%$ were overweight and $6 \%$ were obese. In early adolescence (average age 11 years) the prevalence of overweight was around $18.4 \%$ and of obesity was $8.1 \%$. In the next age group (mean age 15.6 years) the prevalence of overweight was $4.3 \%$ and obesity $2.9 \%$. According to the IOTF criteria, the prevalence of overweight was $16.1 \%$ and obesity $2.4 \%$. The prevalence of overweight according to the WHO criteria was $15.6 \%$ and that of obesity was $9.3 \%$ [15].

Framed in the Child and Youth Health Consultations, more specifically in the Consultation of the Global Health Examination, a study was carried out on the prevalence of overweight and childhood obesity in children between 5 and 6 years old, with the reference area the Sete Rios Health Center in Lisbon, from 2011 to 2013, with the re-

Prevalence of Childhood Obesity in Portugal sults published in 2015. The CDC and WHO criteria were used to assess BMI with 344 global health examinations performed, including 184 male (53.5\%) and 160 female children $(46.5 \%)$. Of the children who participated in the study, $73.5 \%$ were 5 years old and $26.5 \%$ were 6 years old. It was found that according to the CDC criteria the prevalence of overweight was $17 \%$ and of childhood obesity was $21 \%$. In male children, the prevalence of overweight was $10 \%$ and obesity $21 \%$; in females the prevalence of overweight was $25 \%$ and obesity $21 \%$. The results according to the WHO criteria revealed a prevalence of overweight of $21 \%$, and $15 \%$ for childhood obesity. In male children the prevalence of overweight was $17 \%$ and of obesity was $15 \%$, while in females overweight had a prevalence of $25 \%$ and obesity $16 \%$ [16].

In the city of Viseu, a study was carried out in 2013 involving 72 children aged 8 and 11 years old, evaluated by the CDC criteria. The findings revealed $18.1 \%$ of the sample to be overweight and $19.4 \%$ obese. The distribution of the prevalence of obesity according to sex indicated that in females 19.4\% were overweight and 29\% obese, and in males $17.1 \%$ were overweight and $12.2 \%$ obese [17].

Another study carried out at the national level in 17 Portuguese cities between 2007 and 2009 was integrated in the "National Childhood Obesity Tracking Day" program. The results were published in 2016 and the sample consisted of 6,175 children and adolescents between the ages of 2 and 18 years. BMI was evaluated according to the WHO, CDC, and IOTF criteria. The results revealed that, according to the CDC criteria, the prevalence of overweight was $18.7 \%$ and obesity was $13.5 \%$, with overweight and obesity in the child age group ( $<10$ years) being 20.2 and $15.9 \%$, respectively, and 14.8 and $7.1 \%$ in adolescents ( $>10$ years). The WHO criteria revealed a prevalence of overweight of $14.9 \%$ and obesity of $20.6 \%$. Using the IOTF criteria, the prevalence of overweight was $7.2 \%$ and of obesity was $20.2 \%$ [18].

The Portuguese Health Behaviour in School-Aged Children (HBSC) program conducted a study on the prevalence of childhood obesity in the years 2002, 2006, and 2010. The sample consisted of 4,138 male children and 4,472 female children aged between 11 and 17 years attending schools in different regions of Portugal (Alentejo, Algarve, Centro, Lisbon, Norte, and Madeira), and whose BMI was assessed according to the WHO and IOTF criteria. For adolescents aged 11-13 years, according to the IOTF criteria, the prevalence of overweight and obesity was $23.5 \%$ in 2002 and $20.7 \%$ in 2010 , showing a decreasing trend. When assessing BMI with the WHO 
criteria, the prevalence of overweight (including obesity) went up from $28.4 \%$ in 2002 to $32.4 \%$ in 2010 . For the ages between 15 and 17 years, the prevalence of overweight (including obesity) increased from $13.9 \%$ in 2002 to $16.8 \%$ in 2010 using the IOTF criteria. With the WHO criteria the trend was the same, increasing from $14.8 \%$ in 2002 to $18.2 \%$ in $2010[19,20]$.

In the northern region of Portugal, specifically in the Municipality of Vila Nova de Gaia, a study on the prevalence of childhood obesity was carried out including 8,974 children aged between 3 and 13 years who attended preschool education and the first cycle of basic education in the academic year 2013/2014. Using the IOTF criteria to assess the BMI of the total sample, it was found that the prevalence of obesity was lower, at $12.16 \%$. Using the WHO criteria gave a prevalence of obesity of $15.28 \%$, and according to the CDC criteria this percentage was $22.14 \%$. In the prevalence of childhood obesity distributed by sex, it appears that the values were higher in boys, being $13.94 \%$ according to the IOTF criteria, $16.67 \%$ according to the WHO criteria, and $22.97 \%$ according to the CDC criteria. Girls had a prevalence of obesity of $10.28 \%$ (IOTF criteria), $13.8 \%$ (WHO criteria), and $21.27 \%$ (CDC criteria). When the ages were subdivided, it was found that in children under 5 years of age the prevalence of obesity was $8.44 \%$ according to the IOTF criteria, $2.52 \%$ using the WHO criteria, and $18.59 \%$ according to the CDC criteria. For children between 5 and 13 years old, the IOTF criteria revealed a prevalence of obesity of $11.9 \%$, while the prevalence of obesity assessed using the WHO criteria was $17.54 \%$ and according to the CDC was $22.77 \%$ [21].

A study carried out in the central region of Portugal, more specifically in the city of Coimbra and municipality of Lousã, evaluated the prevalence of childhood obesity in 793 children within the 6- to 10-year old age group. The prevalence of overweight (including obesity) was revealed to be $21.9 \%$, with $15.9 \%$ of children classified as overweight and $6.1 \%$ with obesity. Girls had a higher prevalence of overweight (including obesity; 25\%) than boys (18.7\%) [22].

In 2018, an article was published which reported data on the prevalence of childhood obesity obtained through the National Food and Physical Activity Survey (IAN AF 2015-2016). This survey was carried out in mainland Portugal and applied to the general population, including 5,102 individuals aged between 3 months and 84 years, of which 935 were children aged from 3 months to 17 years. $\mathrm{BMI}$ was assessed according to the WHO criteria. The data revealed that $23 \%$ of the children evaluated were under 10 years old and $11 \%$ were adolescents. Of children under the age of 10 years, $17.4 \%$ were overweight and $7.7 \%$ were obese. Among adolescents aged 10-17 years, $23.6 \%$ were overweight and $8.7 \%$ were obese $[3,23]$.

The Childhood Obesity Surveillance Initiative Program (COSI Portugal), directed by the Instituto Nacional de Saúde Dr. Ricardo Jorge in collaboration with the Direção Geral de Saúde, contributes to the child nutritional study integrated in the study by the WHO for Europe (COSI/WHO Europe). This study has been carried out in mainland Portugal since 2008. In 2019, 7,210 school-age children in the first cycle of basic education participated in the study. Based on the WHO criteria, COSI Portugal 2019 found that from 2008 to 2019 there was an $8.3 \%$ reduction in the prevalence of overweight (from 37.9 to $29.6 \%$ ) and of childhood obesity from $15.3 \%$ in 2008 to $12 \%$ in 2019 (a reduction of 3.3\%). The prevalence of childhood obesity increased with age: $15.3 \%$ of children aged 8 years had obesity in 2018/2019, while $10.8 \%$ of 6 -year-old children were obese. Girls had a higher prevalence of overweight (including obesity) than boys - in girls $29.5 \%$ were overweight and $10.6 \%$ were obese. Considering the country's regions, the Algarve had the lowest prevalence of overweight (21.8\%), and the Azores had the highest prevalence (35.9\%). The Alentejo region had the lowest prevalence of childhood obesity (9.7\%). All Portuguese regions showed a decrease in the prevalence of obesity from 2008 to 2019 [2].

\section{Conclusion}

The data obtained in the present narrative review of the literature are of great importance because, although the high prevalence of childhood obesity in Portugal was already known, data from different studies carried out in the country reveal that the prevalence of overweight (including obesity) ranges from 20 to $40 \%$ and the prevalence of obesity ranges from 10 to $15 \%$.

The results of the articles selected and published in the last 10 years allow us to understand the trend of childhood obesity in Portugal in recent years. Some results refer to research data prior to the date of publication of the articles, i.e., surveys of the prevalence of obesity carried out in different years, which allows us to analyse the evolution of the prevalence of childhood obesity in Portugal. The trend is decreasing, that is the global prevalence of childhood obesity has been decreasing in recent years; however, although this is good news, the results of the prevalences are still worrisome since the prevalence of overweight (including obesity) ranges from 20 to $40 \%$. 
It is not possible to make a direct comparison of the results of the prevalence of childhood obesity in the different articles since different criteria for assessing the $\mathrm{BMI} /$ nutritional status of children were used, namely the criteria of the WHO, CDC, IOTF, and French percentile curves, resulting in disparate results that can be difficult to interpret and compare. It is thus important to standardize a universal method of assessing children's nutritional status worldwide. Even when we try to compare results from different studies using the three criteria, it does not allow us to see if there is a uniform trend in the results. It is not possible to affirm the prevalence of childhood obesity when the same sample evaluated (for example) with the WHO criteria has a tendency to always be higher than the prevalence of obesity evaluated with the CDC criteria. This emphasizes the need to standardize the assessment of children's nutritional status in order to allow results to be compared and a more reliable analysis to be made of trends in their evolution. On the other hand, in addition to using different BMI assessment criteria, the studied samples focus on children of different ages, which does not allow the comparison of data from different studies even in children of similar ages and necessitates the generalizing of results for those ages that do not include the same age ranges. However, we were able to observe the prevalence trends in these age groups and also with regard to sex.

Analysing the results of the narrative review in general, it was noticed that there is a tendency to carry out studies on the prevalence of childhood obesity in Portugal in the preschool and school population. In most of the articles selected for this narrative, the sample focused on children belonging to the age group from 5 to 10 years old, some articles present samples of adolescents or the age groups of 11-13 and 13-17 years. There were 3 studies with a more comprehensive sample that included the age group from 2 to 18 years, and only 1 study was found that included children from 0 to 2 years old.

It is important to expand the prevalence studies in this age group, since the recommendations of the WHO for the prevention of childhood obesity start from birth, namely with regard to food (through the promotion of breastfeeding) and physical inactivity and physical activity, in which there are already good practice guidelines with the objective of preventing childhood obesity. Analysing the trend of the prevalence of childhood obesity in relation to age, we can perceive through the analysis of the results of the selected articles that the prevalence of childhood obesity is higher in the ages between 6 and 10 years compared to the prevalence among adolescents.

Prevalence of Childhood Obesity in Portugal
When analysing the trend of childhood obesity in relation to sex, in most studies there are no statistically significant differences in this relationship. However, in studies that analyse this relationship, the trend is that the global prevalence of childhood obesity is higher in females.

When analysing and comparing data from studies that used the CDC BMI assessment criteria, we realized that we cannot compare or generalize the results because 5 studies were carried out at the local level and 2 at the national level. However, it appears that obesity in these studies tends to be more prevalent in males, and in children aged between 5 and 11 years old obesity is more prevalent than being overweight.

In studies using the IOTF criteria, which included 3 carried out at the local level and 2 at the national level, the prevalence of obesity and overweight in the ages between 2 and 10 years old tended to be higher in females. For the ages between 10 and 18 years the prevalence of overweight was higher than that of obesity. A study carried out in Portugal in 2016 pointed to a decrease in the prevalence of obesity and overweight compared to 2002 in children aged 11-13 years. Conversely, in the ages between 15 and 17 years there was an increase in prevalence compared to 2002.

The WHO criteria were used in 4 studies conducted at the local level and 2 at the national level. One of the studies carried out at the national level indicated that the prevalence of overweight and obesity has dropped in the last 10 years in children aged between 6 and 10 years. Another study that obtained results in 2002 and 2018 showed that the reverse is true in children aged 11-17 years, with an increased prevalence of overweight and obesity in 2018 compared to 2002. Studies at the local level that focused on children aged 5-12 years suggest overweight being more prevalent in relation to obesity.

Another observation that we can make from this analysis of the literature is that there are studies on the prevalence of childhood obesity carried out at the national level and studies carried out at the local level (cities/localities). The studies carried out at national level are integrated in projects/programs being implemented in Portugal, such as the COSI for Europe Surveillance System, the National Food and Physical Activity Survey (IAN AF 2015-2016), and the Health Behaviour in School-Aged Children (HBSC) Program. In relation to studies carried out at the local level, it appears that there is a greater concern for conducting these studies in the central and northern regions of the country, with no local studies carried out in the southern region of the country (Alentejo and Algarve). 
The data presented reinforce the urgent need for monitoring and implementation of measures to prevent childhood obesity involving the whole community, namely health institutions, teaching institutions, institutions where children stay (holiday camps, etc.), local authorities, and families. Caring for the health of the population begins before birth. Concern about the increase in the number of cases of childhood obesity is increasingly a public health issue. Identifying, evaluating, and intervening in this problem is an ever more urgent need. Taking care of everyone is taking care of everyone.

\section{Acknowledgments}

We thank the Portuguese Order of Nurses for access to the electronics platforms and Sarah Jane Parson for reviewing and correcting the English version of the text.

\section{Conflict of Interest Statement}

The authors have no conflicts of interest to declare.

\section{Funding Sources}

This study did not receive any funding.

\section{Author Contributions}

F.F. wrote the paper. F.F., D.C., F.P., J.M., and J.F. contributed to the research and selection of articles included in this narrative review of the literature. All authors read and contributed with their knowledge to the writing of the paper.

\section{References}

1 World Health Organization. Report of the Commission on Ending Childhood Obesity. Geneva: World Health Organization; 2016.

2 Rito A, Cruz de Sousa R, Graça P. Childhood Obesity Surveillance Initiative: COSI Portugal 2019. Lisbon: Instituto Nacional de Saúde Doutor Ricardo Jorge; 2019.

3 Oliveira A, Araújo J, Severo M, Correia D, Ramos E, Torres D, et al.; by the IAN-AF Consortium. Prevalence of general and abdominal obesity in Portugal: comprehensive results from the National Food, Nutrition and Physical Activity Survey 2015-2016. BMC Public Health. 2018 May; 18(1):614.

4 Juonala M, Magnussen CG, Berenson GS, Venn A, Burns TL, Sabin MA, et al. Childhood adiposity, adult adiposity, and cardiovascular risk factors. N Engl J Med. 2011 Nov; 365(20): 1876-85.

5 Souza MT, da Silva MD, de Carvalho R. Revisão integrativa: o que é e como fazer. Einstein. 2010;8(1):102-6.

6 Kuczmarski RJ, Ogden CL, Guo SS, Grummer-Strawn LM, Flegal KM, Mei Z, et al. 2000 CDC Growth Charts for the United States: methods and development. Vital Health Stat 11. 2002 May;11(246):1-190.

7 Cole TJ, Bellizzi MC, Flegal KM, Dietz WH. Establishing a standard definition for child overweight and obesity worldwide: international survey. BMJ. 2000 May;320(7244): $1240-3$.

8 Kêkê LM, Samouda H, Jacobs J, di Pompeo C, Lemdani $\mathrm{M}$, Hubert $\mathrm{H}$, et al. Body mass index and childhood obesity classification systems: a comparison of the French International Obesity Task Force (IOTF) and World Health Organization (WHO) references. Rev Epidemiol Sante Publique. 2015 Jun;63(3):173-82.
9 World Health Organization. Obesity and overweight. [Internet]. Geneva: World Health Organization; 2020. [cited 2020 jun 23]. Available from: https://www.who.int/news$\mathrm{room} /$ fact-sheets/detail/obesity-and-overweight.

10 Prazeres T, Fonseca JL. Rastreio da obesidade infantil: três anos de jornadas nacionais. Acta Pediatr Port. 2010;41(3):122-6.

11 Lourenço A, Gama A, Nogueira H, MourãoCarvalhal I, Ferrão M, Rosado V, et al. Ambiente residencial e obesidade infantil: análise exploratória no distrito de Aveiro. Cad Geogr. 2011;30:222-37.

12 Antunes A, Moreira P. Prevalência de excesso de peso e obesidade em crianças e adolescentes Portugueses. Acta Med Port. 2011;24(2): 279-84.

13 Venâncio P, Aguilar S, Pinto G. Obesity in children in Portugal: a cross-sectional study. Rev Port Med Geral Fam. 2012;28(6):410-6. Portuguese.

14 Ferreira PJ, Lopes LS. Obesidade infantil: estudo em crianças num ATL. Millenium. 2012; 42:105-25.

15 Brito SD, Viveiro AC, Moleiro P. Obesidade e sobrepeso numa amostra de adolescentes da cidade portuguesa de Leiria: uma questão de curvas? Rev Port Endocrinol Diabetes Metab. 2014;9(2):116-21.

16 Baptista T, Pereira de Matos I, Baptista Coelho P. Prevalence of overweight and obesity in children attending the global health examination for 5- to 6-year-olds. Acta Pediatr Port. 2015;46:109-12.
17 Amaral A, Melão N. O perfil de saúde de crianças vigiadas em consultas de cuidados primários na cidade de Viseu, Portugal. Rev Port Saude Publica. 2016;34(1):53-60.

18 Viveiro C, Brito S, Moleiro P. Sobrepeso e obesidade pediátrica: a realidade portuguesa. Rev Port Saude Publica. 2016;34(1):30-7.

19 Marques A, de Matos MG. Trends in prevalence of overweight and obesity: are Portuguese adolescents still increasing weight? Int J Public Health. 2016 Jan;61(1):49-56.

20 Gaspar de Matos M, Simões C, Tomé G, Camacho I, Ferreira M, Ramiro L, et al. A saúde dos adolescentes: relatório do estudo HBSC 2010. Lisbon: Centro de Malária e outras Doenças Tropicais, Instituto de Higiene e Medicina Tropical, Universidade Nova de Lisboa, Faculdade de Motricidade Humana, Universidade de Lisboa; 2012.

21 Camarinha B, Graça P, Nogueira PJ. Prevalence of pre-obesity/obesity in pre and basic school children at Vila Nova de Gaia, Portugal. Acta Med Port. 2016 Jan;29(1):31-40. Portuguese.

22 Rodrigues D, Padez C, Machado-Rodrigues AM. Prevalence of abdominal obesity and excess weight among Portuguese children and why abdominal obesity should be included in clinical practice. Acta Med Port. 2018 Mar; 31(3):159-64.

23 Lopes C, Torres D, Oliveira A, Severo M, Alarcão V, Guiomar S, et al. Inquérito Alimentar Nacional e de Atividade Física, IANAF 2015-2016: relatório metodológico. Porto: Universidade do Porto; 2017. 